\title{
Sensorless Control of Outer Rotor Brushless DC Motor With Back-EMF Observer for Drone
}

\author{
Ali Sinan Cabuk
}

\begin{abstract}
The outer rotor brushless direct current motor, which is a highly speed, efficiently, silence and long-life motor, is the most popular motor for drones. Control methods of this type of motor is the most important parameter to be considered. The hall effect sensors, that used in BLDC motor, are not trustable in control applications therefore the back-EMF observer method can be operated for sensorless control. Reducing the production cost of the drive for drone applications is one of the primary goals of manufacturers. Manufacturing cost reduction is often achieved by eliminating driver auxiliary components such as sensors. The use of these sensors, which are important for the detection of rotor position, has been eliminated with sensorless driver designs. This study presents a sensorless outer rotor BLDC motor driver algorithm with back-EMF observer with motor input terminal current and DC bus voltage independent of rotor speed. The sensorless driver model proposed in the study was implemented for a $330 \mathrm{~W}$ drone motor with a rated voltage of $14.8 \mathrm{~V}$. The proposed sensorless control algorithm is proved by MATLAB/SIMULINK results.
\end{abstract}

Index Terms-Back-EMF observer, sensorless control, outer rotor BLDC motor, drone.

\section{INTRODUCTION}

$\mathrm{T}$ HE USE of ground-controlled aircraft (drones) is increasing day by day. These vehicles have many uses such as observation, military activity, racing, cargo, emergency and mapping.

Since the equipment in the systems of unmanned aerial vehicles does not have a sufficient level of development, their use has been restricted until today [1]. The equipment of drones has also improved with the effect of technological developments. In recent years, it has started to take a place in daily life thanks to the increasingly developing microcontroller elements and batteries with increasing energy density. Thus, it is becoming more and more important with new emerging areas of use such as rapid seeding and control of large planting areas in agricultural areas, interfering with fires in the upper floors of skyscrapers in daily life, and distribution of food and cargo $[2,3]$.

ALI SINAN CABUK, is with Istanbul Technical University, Faculty of Electrical and Electronics Engineering, Department of Electrical Engineering, Istanbul, Turkey (e-mail: ascabuk@itu.edu.tr).

(iD https://orcid.org/ 0000-0002-6329-3715

Manuscript received June 28, 2021; accepted September 21, 2021. DOI: $\underline{10.17694 / \text { bajece. } 958760}$
They provide benefits in many areas, especially in shortening the work time, reducing the cost and providing security with the use of drones. The equipment on the drone body generally consists of four brushless direct current motors, propellers, electronic speed controller, flight controller, battery and remote-control system. Depending on the purpose of use, equipment such as cameras can be added to their equipment $[4,5]$.

Unlike conventional DC motors, brushless DC (BLDC) motors require electronic commutation. In order for electronic commutation to occur, the position of the magnets in the rotor of the brushless direct current motor must be transferred to the microcontroller $[6,7,8]$. The rotor position can be transmitted in two ways: with and without sensors. In the sensor method, the rotor position is transferred by adding a sensor to the motor. Control systems made with this method have many disadvantages such as high cost, construction complexity, cable requirement (for sensors inside the motor), low reliability, and difficulty in mounting the sensor to the motor. To avoid these disadvantages, sensorless methods have been developed. In addition to the many advantages of sensorless control systems, it also has difficulties in creating a control algorithm $[9,10]$.

Sensorless control systems contain different algorithms. One of these methods is to find the Zero-Crossing Point (ZPC) by comparing the back-EMF signal with DC bus voltage. In this method, fluctuations that occur as a result of the direct current busbar terminal voltage being affected by motor movements are not a preferred method because they cause instability in motor control [11]. The disadvantages of the zero-cross point detector method are solved by adding a low-pass filter. However, due to the low-pass filter structure, its use is not preferred because it causes back EMF errors [12]. Another control method is fielddirected control. Complex algorithm expressions required for field-oriented control cause limited use due to memory size in microprocessors [13]. In the 3rd Harmonic detection method, which is another control method, the fact that the 3rd Harmonic has 3 times the frequency of the 1st Harmonic caused errors due to the low-pass filter, thus reducing a sensitivity of this system [14]. Apart from these disadvantages, starting the motor becomes a problem as a result of the absence of the back emf signal at low speeds.

In this study, the back EMF observer structure was used to both measure the back EMF at low speeds and to eliminate the negativities in the literature. Lithium battery is used as direct current busbar and $330 \mathrm{~W}, 14.8 \mathrm{~V}$ outer rotor BLDC motor is used with back EMF signal observer. In this sensorless control 
BALKAN JOURNAL OF ELECTRICAL \& COMPUTER ENGINEERING, Vol. 9, No. 4, October 2021

method modeled in MATLAB/Simulink, the drone is considered to carry a low load like mail. The parameters used throughout the study were arranged according to this drone type.

\section{MATHEMATICAL MODELLING OF BLDC MOTOR}

BLDC motors, which have been widely used in recent years, are also used in unmanned aerial vehicles and especially drones. The outer rotor BLDC motor, that is external rotor, is the most preferred electric motor type in these vehicles. The working principle of the outer rotor BLDC motor is relied on on the interaction of the magnetic field generated via an outer rotor with the magnetic field generated via a stator, thus synchronizing it. In order to ensure this synchronization, the stator winding is switched on and off. The switching of the windings is accomplished electronically using power electronics semiconductors.

The voltage equations of the outer rotor BLDC motor are given in Equation 1,2,3. In these equations, the stator resistance and inductance are considered equal for each phase $\left(R_{a}=R_{b}=R_{c}=R\right)\left(L_{a}=L_{b}=L_{c}=L\right)[15,16]$.

$$
\begin{aligned}
& u_{a}=R i_{a}+L \frac{d i_{a}}{d t}+e_{a} \\
& u_{b}=R i_{b}+L \frac{d i_{b}}{d t}+e_{b} \\
& u_{c}=R i_{c}+L \frac{d i_{c}}{d t}+e_{c}
\end{aligned}
$$

Where $i_{a}, i_{b}$ and $i_{c}$ are currents of phases, $R$ is resistance of phase, $L$ is inductance of phase, $e_{a}, e_{b}$ and $e_{c}$ are back-EMF values, $u_{a}, u_{b}, u_{c}$ are voltages of phases.

When an outer rotor BLDC motor starts to rotate, back emf is produced as a trapezoidal in each winding. The currents of three-phase fed to the BLDC motor are in a form of a square wave for constant torque generation. The back-EMF produced related to the rotor position as in Equation 4.

$$
E=K_{e} \omega
$$

where $K_{e}$ is constant of back-EMF, $\omega$ is the rotor angular velocity. The instantaneous back-EMF is

$$
\begin{aligned}
& e_{a}=f_{a}(\theta) E \\
& e_{b}=f_{b}(\theta) E \\
& e_{c}=f_{c}(\theta) E
\end{aligned}
$$

where $\theta$ is position of the rotor.

The expression $f(\theta)$ for each phase;

$$
\begin{aligned}
& f_{a}(\theta)=\left\{\begin{array}{lr}
\left(\frac{6}{\pi}\right) \theta & (0 \leq \theta<\pi / 6) \\
1 & (\pi / 6 \leq \theta<5 \pi / 6) \\
-\left(\frac{6}{\pi}\right) \theta+6 & (5 \pi / 6 \leq \theta<7 \pi / 6) \\
-1 & (7 \pi / 6 \leq \theta<11 \pi / 6) \\
\left(\frac{6}{\pi}\right) \theta-12 & (11 \pi / 6 \leq \theta<2 \pi)
\end{array}\right\} \\
& f_{b}(\theta)=\left\{\begin{array}{cr}
-1 & (0 \leq \theta<\pi / 2) \\
\left(\frac{6}{\pi}\right) \theta-4 & (\pi / 2 \leq \theta<5 \pi / 6) \\
1 & (5 \pi / 6 \leq \theta<9 \pi / 6) \\
-\left(\frac{6}{\pi}\right) \theta+10 & (9 \pi / 6 \leq \theta<11 \pi / 6) \\
1 & (11 \pi / 6 \leq \theta<2 \pi)
\end{array}\right\} \\
& f_{c}(\theta)=\left\{\begin{array}{cr}
1 & (0 \leq \theta<\pi / 6) \\
-\left(\frac{6}{\pi}\right) \theta+2 & (\pi / 6 \leq \theta<\pi / 2) \\
-1 & (\pi / 2 \leq \theta<7 \pi / 6) \\
\left(\frac{6}{\pi}\right) \theta-8 & (7 \pi / 6 \leq \theta<9 \pi / 6) \\
1 & (9 \pi / 6 \leq \theta<2 \pi)
\end{array}\right\}
\end{aligned}
$$

The rotation direction of the motor must be observed in the $\theta$ position conditions given in Equations 8,9 and 10. The torque value produced by each phase is corresponding to the related phase current and depends on the rotor position. The overall electromagnetic torque via the motor is given by Equation 11.

$$
T_{e}=K_{t}\left\{f_{a}(\theta) i_{a}+f_{b}(\theta) i_{b}+f_{c}(\theta) i_{c}\right\} \omega
$$

where $K_{t}$ is constant of torque.

The equation of motion of a simple system is as in Equation 12.

$$
T_{e}=J\left(\frac{d \omega}{d t}\right)+B \omega+T_{L}
$$

where $J$ is inertia moment of the motor, $T_{L}$ is load torque $[9,15,16]$.

\section{SENSORLESS CONTROL OF OUTER ROTOR BLDC MOTOR}

\section{A. Back EMF Sensing}

Although the use of sensors for the rotor position data of the outer rotor BLDC motor provides easy control, it causes disadvantages such as cost and manufacturing difficulties. Sensorless control does not have these disadvantages. Different algorithms are used for sensorless control [17]. In the control of outer rotor BLDC motors used in drones, it is more appropriate to use a sensorless control method due to space limitations and cost factors. In this study, the back EMF observer method was used because it is simple and inexpensive.

This method uses to stimulate two phase winding of an outer BLDC motor windings for a prespecified time. An outer rotor at the time move to align to an exact position. An open-loop 
control system is implemented to speed up the BLDC motor from standstill with a known preliminary position of rotor and a known commutation. The sensorless system senses the Zero Crossing Points (ZCP's) of back-EMF induced in stator windings. The three-phase back EMF ZCP's are detected when one of stator windings are not voltage. The acquired data is operated with the aim of commutation control the winding voltage and energized phase pair operating Pulse Width Modulation (PWM) [8].

One disadvantage of back-EMF method has high frequency noises. Since PWM is used as the switching method, adding a resistor to each phase causes high frequency noises. Therefore, a low-pass filter is given preference to reduce a noise of the signal. The back EMF is obtained by comparing the filtered signal with the neutral reference voltage in a signal comparator. The signal comparator produces a low to high signal when the back-EMF changes from negative to positive, and a high to low signal when the back EMF changes from positive to negative $[8,18]$. Therefore, ZCP's are found as given in Figure 1 by using the back-EMF sensor circuit for each phase.

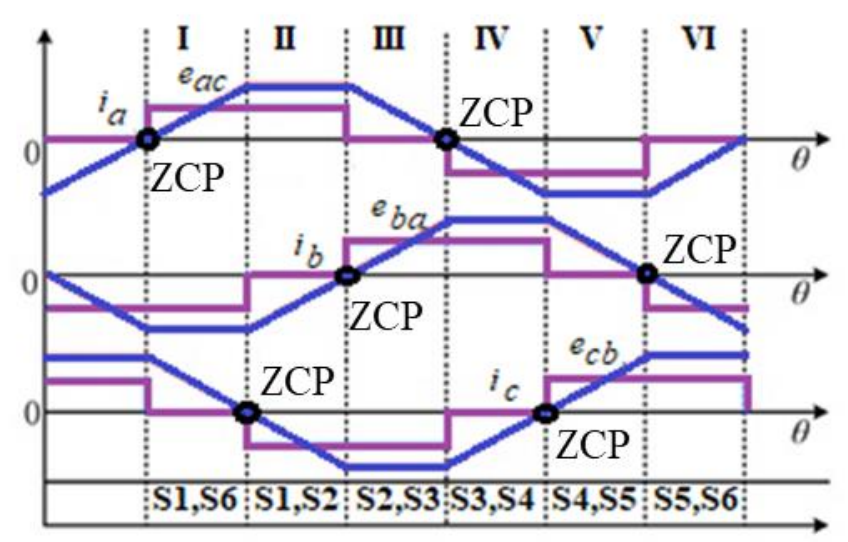

Fig.1 Zero crossing points of the back-EMF [18]

The back-EMF ZPC controls outer rotor BLDC motor driver by finding the point where the back-EMF signal of a deenergized phase passes through zero. This zero crossing begins a timer, that can be ordinary an R-C time constant, allowing the transmission time to be determined for the next switch [18].

In order to minimize the moment ripple, phase current should be given in the region where the phase back EMF is flat region. After the zero-crossing point is found, the commutation point is found with a 30 degree offset. Since each phase is in 120 degrees conduction, one phase is de-energized at all intervals.

\section{B. Sensorless control method}

The proposed method, that is back-EMF sensorless control, is based on the determination of the rotor position using a trapezoidal back-EMF of outer rotor BLDC motor. Due to a back-EMF of the outer rotor BLDC motors are not directly sensed, they are predicted via the input observer. The observer is designed via a back-EMF assumed input of outer rotor BLDC motor drive system [19].

Figure 1 shows the correlation between back-EMF and the commutation moments of the stator winding currents. All
ZCP's of the back-EMF $e_{a c}, e_{b a}$ and $e_{c b} \pi / 6, \pi / 2, \pi, 4 \pi / 3,5 \pi / 3$ and $2 \pi(0)$, correlate with the six commutation points are given in Figure 1.

A formula is required to predict the Back-EMF line using detectable electrical parameters. Assuming the inductances and stator resistances of the three stator windings are equal and symmetrical, the line voltage formulations of the outer rotor BLDC motor are expressed as in Equation13, 14 and 15 [18,19].

$$
\begin{aligned}
& e_{a c}=u_{a c}-R\left(i_{a}-i_{c}\right)-(L-M) \frac{d}{d t}\left(i_{a}-i_{c}\right) \\
& e_{b a}=u_{b a}-R\left(i_{b}-i_{a}\right)-(L-M) \frac{d}{d t}\left(i_{b}-i_{a}\right) \\
& e_{c b}=u_{c b}-R\left(i_{c}-i_{b}\right)-(L-M) \frac{d}{d t}\left(i_{c}-i_{b}\right)
\end{aligned}
$$

where $e_{a c}, e_{b a}$ and $e_{c b}$ are the line back-EMF, $u_{a c}, u_{b a}$ and $u_{c b}$ are the line voltages.

It is seen in Equations 13, 14 and 15 that the back-EMF value is correlated to the phase current, motor parameters and line voltage. The inductance value of the stator changes depending on the rotor position of the motor. It is quite hard to sense this value in real time. Therefore, Equations 13, 14 and 15 should be simplified. The differential terms in Equation 13, 14 and 15 are omitted as they have no effect on the detection of ZCP $[18,19]$. A simplified version of the equations for the motor rotates clockwise;

$$
\begin{aligned}
& e_{a c}=u_{a c}+R\left(i_{c}\right) \\
& e_{b a}=u_{b a}+R\left(i_{a}\right) \\
& e_{c b}=u_{c b}+R\left(i_{b}\right)
\end{aligned}
$$

The simplified version of the equations stated when the motor rotates counterclockwise can be defined as in Equations 19, 20 and 21.

$$
\begin{aligned}
& e_{a c}=u_{a c}-R\left(i_{a}\right) \\
& e_{b a}=u_{b a}-R\left(i_{b}\right) \\
& e_{c b}=u_{c b}-R\left(i_{c}\right)
\end{aligned}
$$

With these simplified formulas, the line back-EMF is calculated. As shown in Figure 2, $H_{A C}, H_{B A}$ and $H_{C B}$ are transformed to digital position signal. These signals of the positions are the same like the signals of the hall position. Digital position signals have a correlative offset from each other by 120 electrical degrees. These can be triggered simply using the commutation action. The commutation takes place during the forward or reverse transition of any of the position signals. Accordingly, the corresponding commutation control procedure for the rotor position and the outer rotor BLDC motor 
can be acquired $[18,20]$. Accordingly, the corresponding commutation control procedure given in Table 1 can be obtained.

TABLE I

COMMUTATION CONTROL METHOD OF THE OUTER ROTOR BLDC MOTOR [18]

\begin{tabular}{|c|c|c|c|c|c|}
\hline $\begin{array}{c}\text { Rotor } \\
\text { Position }\end{array}$ & $\mathrm{H}_{\mathrm{AC}}$ & $\mathrm{H}_{\mathrm{BA}}$ & $\mathrm{H}_{\mathrm{CB}}$ & $\begin{array}{l}\text { Active } \\
\text { Phase }\end{array}$ & $\begin{array}{c}\text { Active } \\
\text { Switches }\end{array}$ \\
\hline VI-I & Forward & 0 & 1 & $+\mathrm{A},-\mathrm{B}$ & S1, S6 \\
\hline $\mathrm{I}-\mathrm{II}$ & 1 & 0 & Backward & $+\mathrm{A},-\mathrm{C}$ & $\mathrm{S} 1, \mathrm{~S} 2$ \\
\hline II-II & 1 & Forward & 0 & $+\mathrm{B},-\mathrm{C}$ & $\mathrm{S} 3, \mathrm{~S} 2$ \\
\hline III-IV & Backward & 1 & 0 & $+\mathrm{B},-\mathrm{A}$ & $\mathrm{S} 3, \mathrm{~S} 4$ \\
\hline $\mathrm{IV}-\mathrm{V}$ & 0 & 1 & Forward & $+\mathrm{C},-\mathrm{A}$ & $\mathrm{S} 5, \mathrm{~S} 4$ \\
\hline $\mathrm{V}-\mathrm{VI}$ & 0 & Backward & 1 & $+\mathrm{C},-\mathrm{B}$ & S5, S6 \\
\hline
\end{tabular}

\section{SimULATiON}

In the study, the outer rotor BLDC motor used in low cost and general-purpose drone applications was used. This type of drones are mostly used for entertainment purposes, cost priority drones. The electric motor of drone data subject to the study are given in Table 2.

TABLE II

PARAMETERS OF THE OUTER ROTOR BLDC

\begin{tabular}{lc}
\hline \multicolumn{1}{c}{ Parameter } & Value \\
\hline Stator Diameter [mm] & 22 \\
Max. Continuous Power [W] & 330 \\
Rated Speed [rpm] & 4235 \\
Operating Voltage Range[V] & $11.1-14.8$ \\
\hline
\end{tabular}

MOSFET or IGBT can be used as switch in BLDC motor driver. This selection is made according to switching frequency range, the motor's voltage and current. While MOSFETs are used in high current and low voltage practices, IGBT is preferred in high voltage high current applications [21]. Since BLDC motors used in drones will operate at low voltage, MOSFET selection would be more ideal. MOSFET is used in the model used in this study. The signals received from the outer rotor BLDC motor driver MOSFETs can be easily accessed with the help of the 3-phase V-I calculator, the voltage and current values of all three phases.

For the MATLAB/Simulink model to be realistic, a load torque of $2.5 \mathrm{Nm}$ is used for the proposed motor model. The voltage and current measurements taken from the motor input were transferred to the back-EMF observer. These signals of the outer BLDC motor can be found according to the input voltage and current values with the back-EMF observer. It is very important for the back-EMF observer to determine the desired moments. The back-EMF observer block diagram is shown in Figure 2.

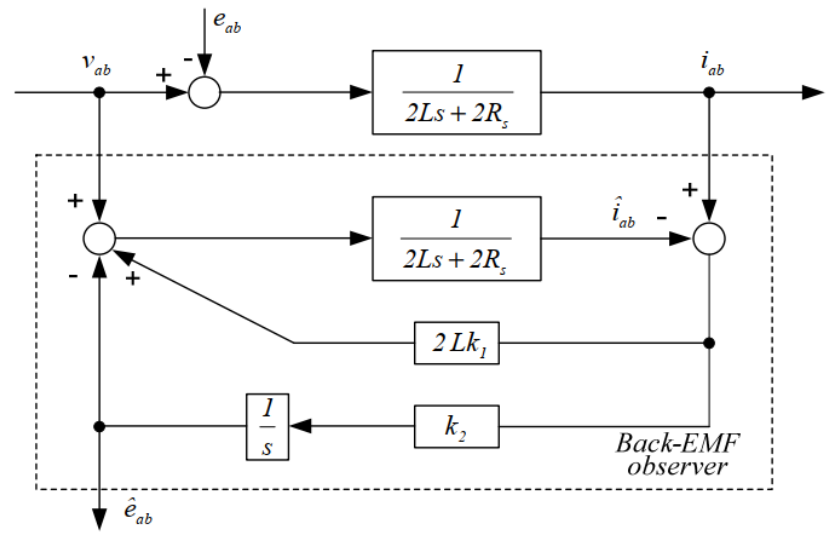

Fig.2 The back-EMF observer block diagram [19]

According to the back-EMF observer block diagram, the MATLAB/Simulink block of back-EMF observer model is given in Figure 3.

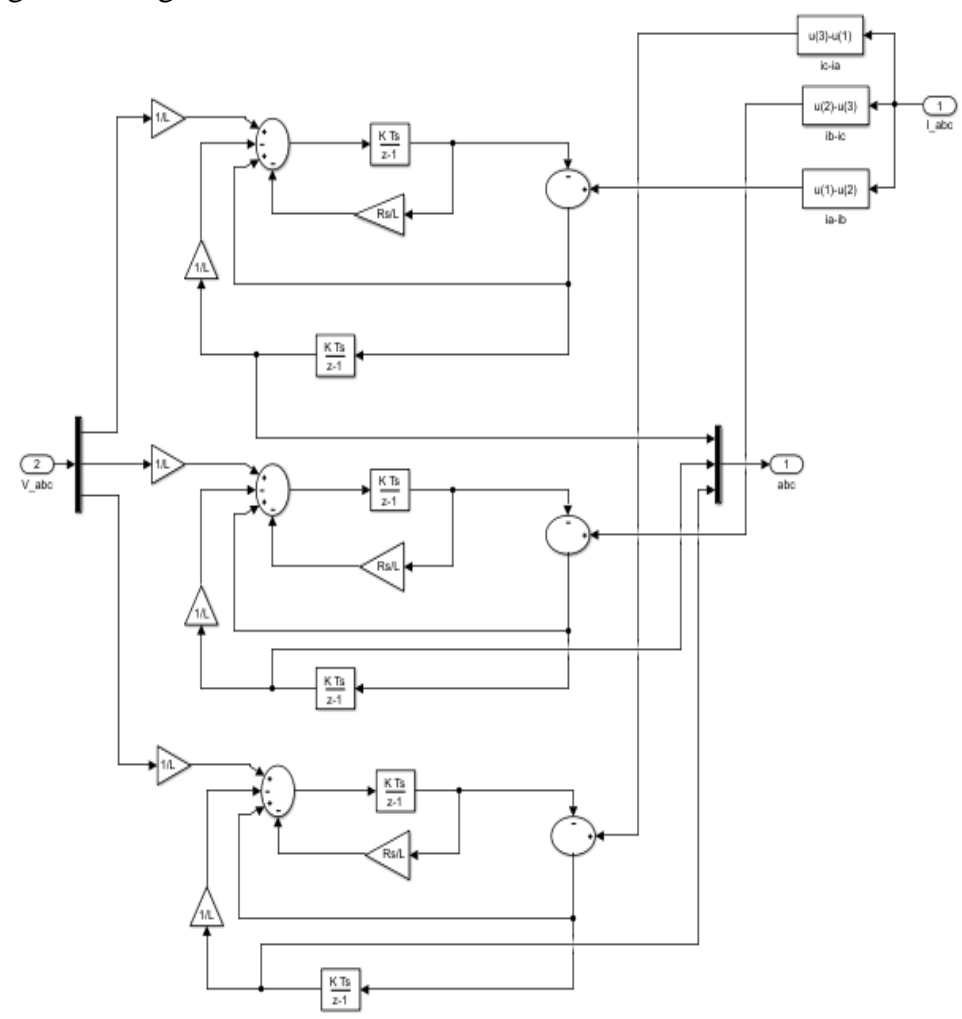

Fig.3 Simulation model of back-EMF observer

ZCP's are determined with "Compare to Zero" in the signal generator block of these signals. Thus, it is provided to generate signal signals to MOSFETs at the desired time.

MATLAB/Simulink of the outer rotor BLDC motor sensorless driver with Equation 1 to 18 was used in the modelling the system. MATLAB/Simulink model of the outer BLDC motor is given in Figure 4 can be created with the equations given before. 


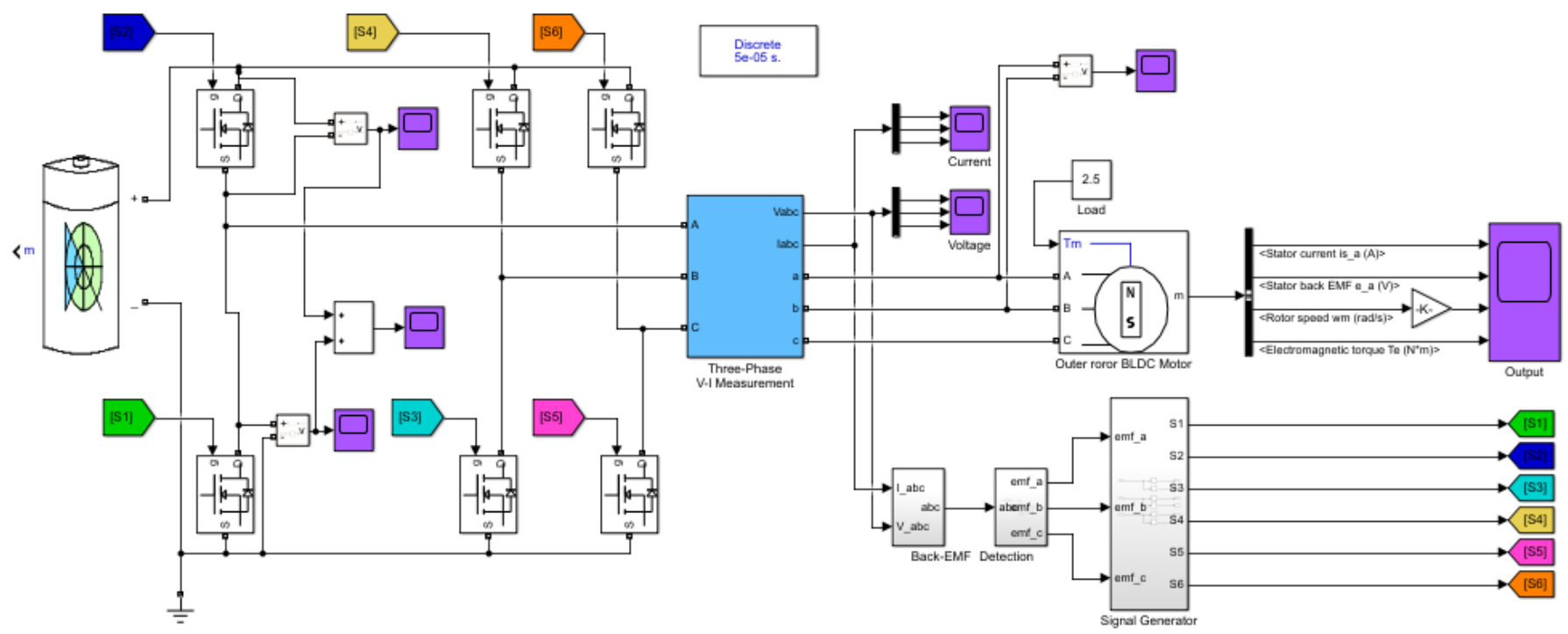

Fig.4 Simulation model for the outer rotor BLDC motor

\section{RESULTS OF SIMULATION}

To verify the operation of the recommended method, MATLAB/Simulink simulations of the outer rotor BLDC motor driver system were carried out with the sensorless control method. The parameters shown in Table 3 were used in this simulation.

TABLE III SIMULATION PARAMETERS

\begin{tabular}{lc}
\hline \multicolumn{1}{c}{ Parameter } & Value \\
\hline Rated Voltage [V] & 14.8 \\
Rated Speed [rpm] & 4235 \\
Number of Poles & 14 \\
Stator Resistance $[\mathrm{m} \Omega]$ & 100 \\
Stator Inductance [mH] & 8.5 \\
\hline
\end{tabular}

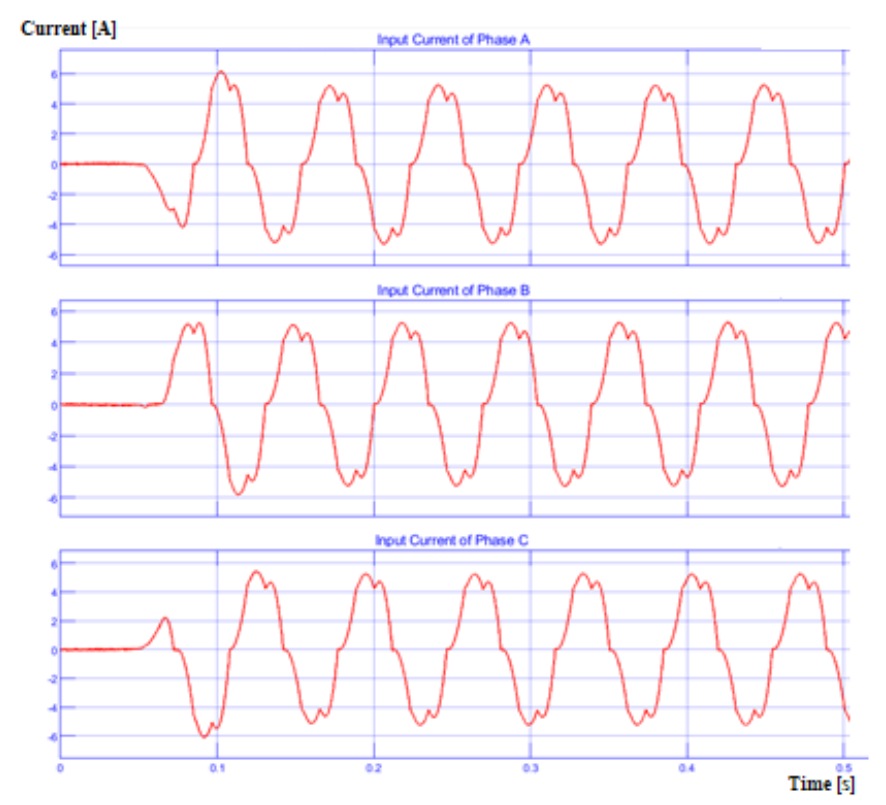

Fig 5. Input currents of outer rotor BLDC motor
After build the MATLAB/Simulink model in Figure 4, the input voltage was determined as $14.8 \mathrm{~V}$ DC voltage, that is the operating voltage range of the outer BLDC motor. DC busbar consists of 4 pieces of $3.7 \mathrm{~V}$ batteries for a realistic approach. As a result of the simulation study, the input current curve and the input voltage curve are as in Figure 5 and 6.

The input currents in Figure 5 are similar to the expected stator currents. At any time "t", 2 phases are in conduction and the other phase is not in conduction. The instantaneous current sums are zero. Figure 6 shows the voltage generated as a result of triggering the MOSFETs by switching the input voltage at certain moments.

When the input voltage and current signals of the model are examined, it is seen that the stator currents occur with areas where the back emf is flat as expected.

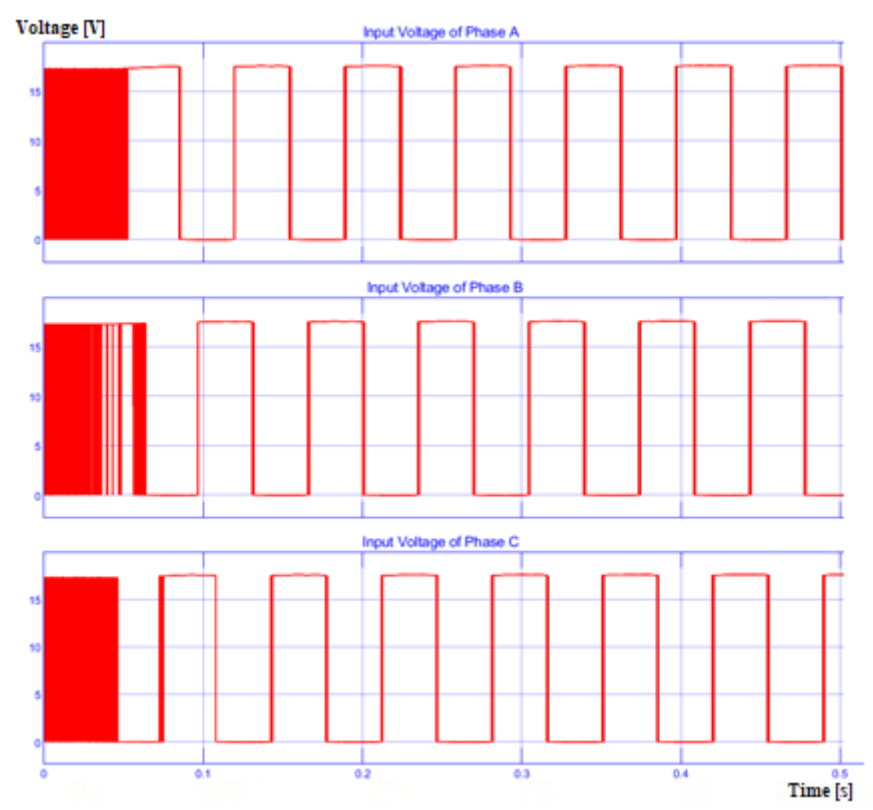

Fig 6. Input voltages of BLDC motor 
As can be seen in Figure 7, the trapezoidal back EMF peak value is almost half of the DC bus voltage. There are 120 degrees positive, 120 degrees negative and 120 degrees transition moments.

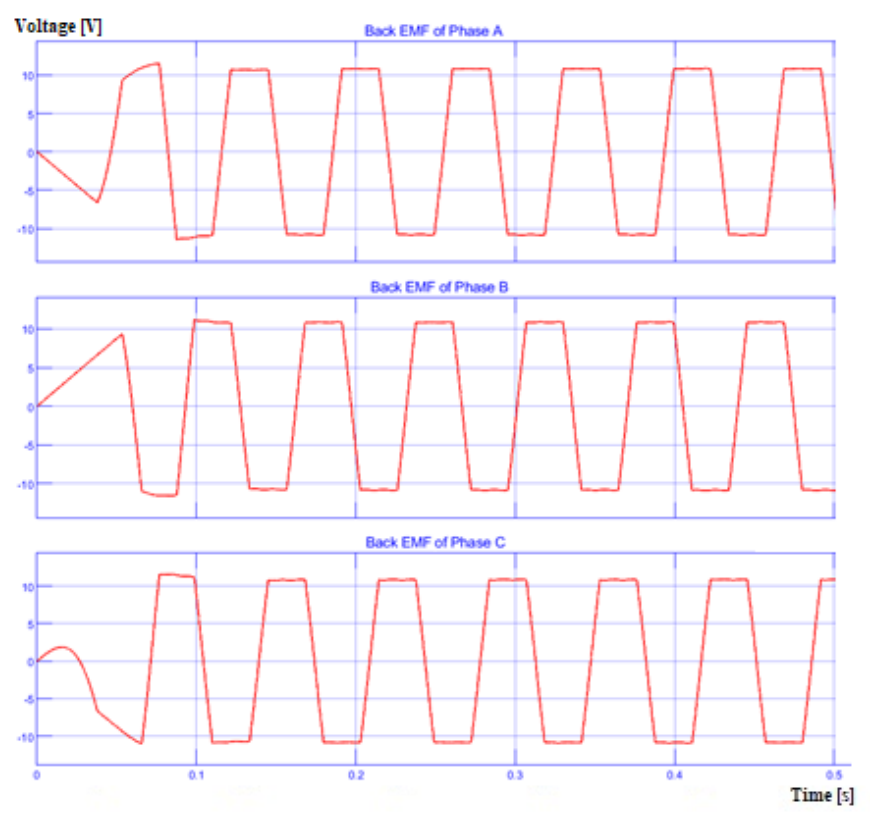

Fig 7. Back EMF of BLDC motor

The outer rotor BLDC motor used for operation is a motor with low $K v$ (constant velocity of a motor). Since it is a lowloaded transport aimed with the drone, this type of motor was preferred in order to be suitable for the long propeller structure. How much torque per ampere will be obtained from drone motors is also related to the $K v$ value of the motor. The lower the $K v$ value, the higher the torque available from the motor per ampere. Large propellers can be fitted as motors with low $K v$ will give high torque. For the same amount of torque, a high $K v$ motor will draw more current than a low $K v$ one.

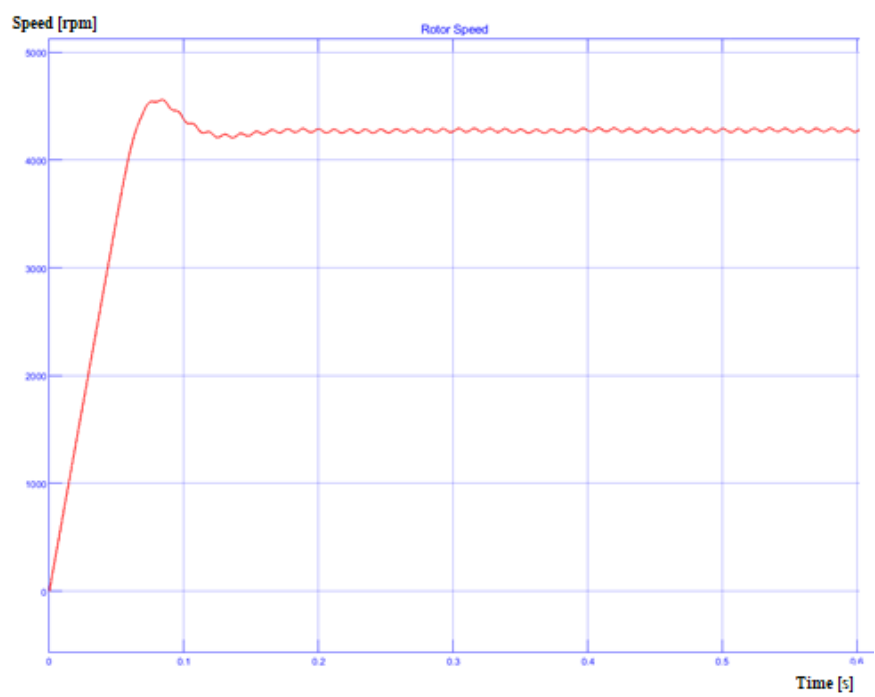

Fig 8. Rotor speed of BLDC motor

It is seen in Figure 8 that the selected motor accelerates to the desired rotor speed according to the $K v$ value and the propeller size. Since the model is open loop, there are very low fluctuations in speed.

Due to the same situation, output torque ripple is seen in Figure 9. It is understood that the obtained moment value is suitable for the load.

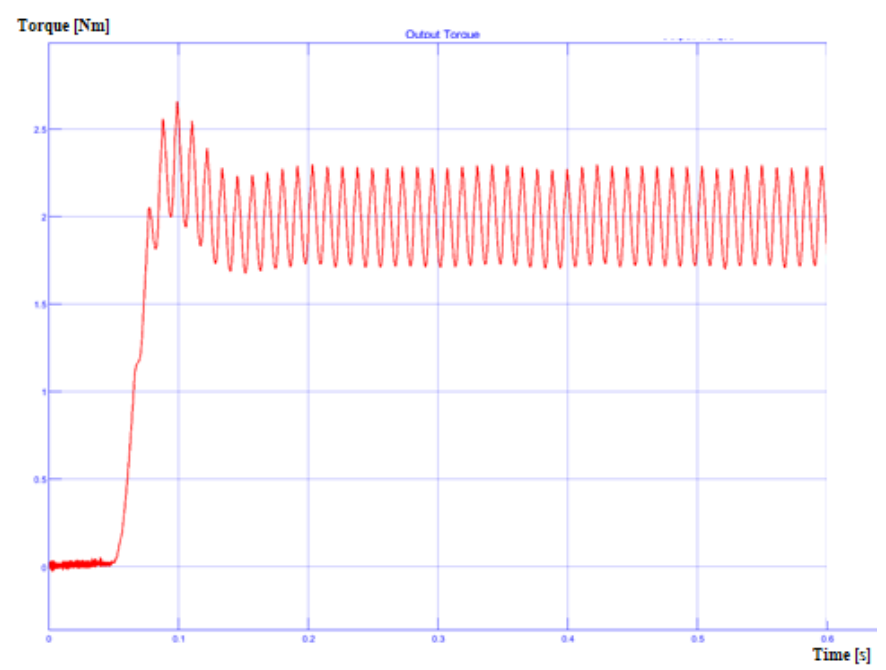

Fig 9. Output torque of BLDC motor

\section{CONCLUSION}

The use of drones is increasing in daily life, industry and military applications. The most important problems of drones are the limited flight times and the difficulties of their control. All of the studies are on the fact that their controls are simpler and cheaper. This article focuses on the sensorless drive method, which is better than sensor drive systems. Sensorless outer rotor BLDC motor driver is modeled with back EMF detection, which is one of the sensorless drone drive methods. This control method has advantages such as cost, simplicity and reliability. In this study, the sensorless operation mode is based on the zero-crossing detection algorithm. The major benefit of back-EMF observer is a simplicity of determining of rotor position. The method uses terminal currents and voltages for rotor position determining. Simulation results are appeared which confirm the suitability of the proposed method.

\section{REFERENCES}

[1] P. Zhu, T. Peng, D. Du, H. Yu, L. Zhang, Q. Hu. "Graph Regularized Flow Attention Network for Video Animal Counting From Drones." IEEE Transactions on Image Processing, vol. 30, 2021, pp. 5339-5351. doi: 10.1109/TIP.2021.3082297.

[2] S. U. Jan, F. Qayum, H. U. Khan. "Design and Analysis of Lightweight Authentication Protocol for Securing IoD." IEEE Access, vol. 9, 2021, pp. 69287-69306. doi: 10.1109/ACCESS.2021.3076692

[3] E. Yanmaz Adam. "Leveraging Connectivity for Coverage in Drone Networks for Target Detection." Balkan Journal of Electrical and Computer Engineering, 7(3), 2019, pp 218-225. doi:10.17694/bajece.503818

[4] V. Araña-Pulido, E. Jiménez-Yguácel, F. Cabrera-Almeida, P. QuintanaMorales. "Triangular Phase Shift Detector for Drone Precise Vertical Landing RF Systems." IEEE Transactions on Instrumentation and Measurement, vol. 70, 2021, pp. 1-8, 2021. doi: 10.1109/TIM.2021.3063772. 
[5] K. Backman, D. Kulić, H. Chung. "Learning to Assist Drone Landings." IEEE Robotics and Automation Letters, vol. 6, no. 2, 2021, pp. 31923199 doi: 10.1109/LRA.2021.3062572.

[6] F. Kazan, R. Akkaya. "The Effect of Increases in User Weight and Road Slope on Energy Consumption in Disabled Vehicle Driven with PMSM", Balkan Journal of Electrical and Computer Engineering, 9(1), 2021, pp. 1-7. doi:10.17694/bajece.783455

[7] M. Çorapsız, H. Kahveci, M. Çorapsız. "Analysis and Suppressing Speed Fluctuations in Brushless DC Motors." Balkan Journal of Electrical and Computer Engineering, 7(3), 2019, pp. 300-310. doi:10.17694/bajece.569774

[8] O. Akar, U. K. Terzi, O. Ozgonenel. "A New Speed Control Technique for a Separately Excited Direct Current Motor by PID Controller", Balkan Journal of Electrical and Computer Engineering, 6, 2018, pp. 1217. doi:10.17694/bajece.410209.

[9] P. Damodharan, K. Vasudevan. "Sensorless Brushless DC Motor Drive Based on the Zero-Crossing Detection of Back Electromotive Force (EMF) From the Line Voltage Difference." IEEE Transactions on Energy Conversion, vol. 25, no. 3, 2010, pp. 661-668. doi: 10.1109/TEC.2010.2041781.

[10] P. Norouzi, Ö. C. Kıvanç, Ö. Üstün. "High performance position control of double sided air core linear brushless DC motor." 10th International Conference on Electrical and Electronics Engineering (ELECO), Bursa Turkey, pp. 233-238. 2017.

[11] J. S. Park, K. Lee, S. G. Lee, W. Kim. "Unbalanced ZCP Compensation Method for Position Sensorless BLDC Motor." IEEE Transactions on Power Electronics, vol. 34, no. 4, 2019, pp. 3020-3024. doi: 10.1109/TPEL.2018.2868828.

[12] D. Arifiyan, S. Riyadi. "Hardware Implementation of Sensorless BLDC Motor Control to Expand Speed Range." 2019 International Seminar on Application for Technology of Information and Communication (iSemantic), pp. 476-481, Semarang, Indonesia, 2019. doi: 10.1109/ISEMANTIC.2019.8884269.

[13] X. Zhang, X. Xie, R. Yao. "Field oriented control for permanent magnet synchronous motor based on DSP experimental platform." The 27th Chinese Control and Decision Conference (2015 CCDC), pp. 18701875, Qingdao, China, 2015. doi: 10.1109/CCDC.2015.7162224.

[14] M. Faeq, D. Ishak. "Anew scheme sensorless control of BLDC motor using software PLL and third harmonic back-emf." 2009 IEEE Symposium on Industrial Electronics \& Applications, pp. 861-865, Kuala Lumpur, Malaysia, 2009. doi: 10.1109/ISIEA.2009.5356344.

[15] R Sreepriya, R. Rajagopal. "Sensorless control of three phase BLDC motor drive with improved flux observer." 2013 International Conference on Control Communication and Computing (ICCC), Thiruvananthapuram, India, pp. 292-297, 2013. doi: 10.1109/ICCC.2013.6731667.

[16] F. Ahmad, M. Pandey, M. Zaid. "Sensorless Control of Brushless DC Motor by Zero-Crossing Detection Pulse Generation with Adaptive Power Factor Control Technique." 2018 IEEE International Conference on Environment and Electrical Engineering and 2018 IEEE Industrial and Commercial Power Systems Europe (EEEIC / I\&CPS Europe), pp. 1-6, Palermo, Italy, 2018. doi: 10.1109/EEEIC.2018.8493648.

[17] Zhang X.Z., Wang Y.N. "A novel position-sensorless control method for brushless DC motors." Energy Conversion and Management, Vol. 52, Issue 3, 2011, pp. 1669-1676.

https://doi.org/10.1016/j.enconman.2010.10.030.

[18] C. Tong, M. Wang, B. Zhao, Z. Yin, P. Zheng. "A Novel Sensorless Control Strategy for Brushless Direct Current Motor Based on the Estimation of Line Back Electro-Motive Force." Energies, vol. 10, no. 9, 2017, pp. 1-20.

[19] T-S Kim, B-G Park, D-M Lee, J-S Ryu, D-S Hyun. "A new approach to sensorless control method for brushless DC motors." International Journal of Control, Automation, and Systems, 6(4), 2008, pp. 477-487.

[20] K. S. Nithin, R. S. Vivek, M. Krishna, A. Purushothaman. "Commutation Torque Ripple Comparison in Cuk Converter Fed Brushless DC Motor Drives with Mode Switching Selection Circuit," 2020 International Conference on Power Electronics and Renewable Energy Applications (PEREA), 2020, pp. 1-6, doi: 10.1109/PEREA51218.2020.9339770.

[21] Y. Wei, X. Du, D. Woldegiorgis, A. Mantooth. "Application of An Active Gate Driver for Paralleling Operation of Si IGBT and SiC MOSFET," 2021 IEEE 12th Energy Conversion Congress \& Exposition - Asia (ECCE-Asia), 2021, pp. 314-319, doi: 10.1109/ECCEAsia49820.2021.9479254

\section{BIOGRAPHIES}

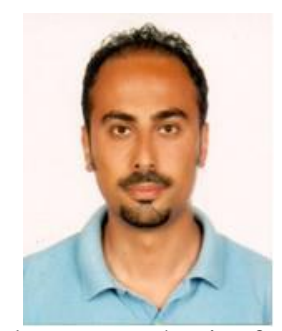

Ali Sinan CABUK was born in Denizli, Turkey on September 11th, 1976. He received the B.S., M.S. and Ph.D. degrees from the Marmara University in Istanbul, Turkey. Currently he is a lecturer in Electrical Engineering Department at Istanbul Technical University in Istanbul, Turkey. He had been studying on his doctorate thesis from 2012 to 2013 at the Department of Electrical Machines, Drives and Automation, Faculty of Electrical Engineering and Computing, University of Zagreb, Croatia. His research interests include electric machines, electric vehicles, power electronic circuit design and simulation, mechatronic system design, automotive mechatronics, robotics and IoT systems. 